\title{
Melanocortin-1 and melanocortin-5 receptors are expressed in cultured mouse peritoneal macrophages
}

\author{
Mitsuyuki Ichinose ${ }^{1 *}$, Gregg T. Nagle 2 , Masatoshi Asai ${ }^{3}$ and Masashi Sawada ${ }^{4}$ \\ 'Department of Welfare Engineering, Faculty of Engineering, Iwate University, Morioka 020-8551, Japan \\ ${ }^{2}$ Marine Biomedical Institute and Department of Anatomy \& Neurosciences, The University of Texas Medical Branch, Galveston, \\ Texas 77555, USA \\ ${ }^{3}$ Department of Physics, 4Department of Physiology, Shimane Medical University, Izumo 693-8501, Japan
}

(Received 24 May 2000; and accepted 15 June 2000)

\begin{abstract}
Adrenocorticotropic hormone (ACTH) belongs to the melanocortin group of related peptides which share a common precursor, pro-opiomelanocortin (POMC). Melanocortin expresses its functional effects by the stimulation of specific seven transmembrane G-protein linked receptors. To date, five melanocortin receptors have been cloned. In the immune system, the production of ACTH in immuno-competent cells has been reported. Because of various physiological effects of ACTH on immuno-competent cells, the hormone might be an intercellular messenger in the immune system. In this study, we report the expression of melanocortin-1 and melanocortin-5 receptors ( $\mathrm{MC1}$ and $\mathrm{MC5}$ ) in cultured mouse peritoneal macrophages. By using a sensitive reverse transcription-polymerase chain reaction (RT-PCR), we demonstrate that these two receptors are specifically expressed in macrophages, whereas expression of other members of the melanocortin receptor family (MC2, MC3 and MC4) was not detected. The sizes of the $\mathrm{MC} 1$ and $\mathrm{MC} 5$ receptor reverse transcription-polymerase chain reaction (RT-PCR) products are identical to the MC1 receptor RT-PCR product in mouse skin and MC5 receptor RT-PCR product in mouse skeletal muscle. The present data suggest that ACTH may modulate macrophage function by activating $\mathrm{MCl}$ and/or MC5 receptors.
\end{abstract}

It has been known that neuroendocrine hormones can modulate immune responses (16). In fact, ACTH suppresses both T-cell-dependent and T-cell-independent antibody synthesis in mouse spleen cells (7). ACTH also enhances growth and differentiation of B-cells (1). Production of interferon- $\gamma($ IFN- $\gamma)$ in T-cells is suppressed by ACTH (8). Activation of macrophages by IFN- $\gamma$ is blocked by ACTH (9). ACTH suppresses the expression of major histocompatibility complex

* Correspondence to Dr Mitsuyuki Ichinose, Department of Welfare Engineering, Faculty of Engineering, Iwate University, Morioka 020-8551, Japan.

Phone \& Fax: 81-19-621-6310;

E-mail: michinos@iwate-u.ac.jp.
(MHC) class II in macrophages (17). Phagocytosis in mouse peritoneal macrophages is inhibited by ACTH (6). However, the macrophage receptors for ACTH have not been well defined. In the present study, we found that cultured mouse peritoneal macrophages expressed $\mathrm{MC} 1$ and MC5 receptors.

Macrophages were collected from male BALB/ cAJcl mice (Nihon Clea, Tokyo; 10-25 weeks old) 5 days after intraperitoneal injection of $4 \mathrm{~mL}$ thioglycollate medium (6). The cells were plated onto dishes (Falcon 3001, Becton Dickinson, Oxnard, CA) at a density of $5 \times 10^{4}$ cells per dish and cultured in RPMI 1640 medium containing $10 \%$ fetal bovine serum, $100 \mu \mathrm{g} / \mathrm{mL}$ streptomycin and 100 units $/ \mathrm{mL}$ penicillin $\mathrm{G}$ (Sigma, St. Louis, 
$\mathrm{MO})$ in a $\mathrm{CO}_{2}$ incubator at $37^{\circ} \mathrm{C}$.

Skin and skeletal muscle was removed from female C57BL/6J mice (Jackson Labs) and frozen in liquid nitrogen. Total RNA was isolated from skin, skeletal muscle, and macrophages by using the single-step method with TRIzol (Gibco BRL) (3). In most experiments, total RNA was pretreated with DNase I to remove traces of genomic DNA. Reverse transcription was performed using $2 \mu \mathrm{M}$ antisense oligonucleotide primers and the SuperScript Preamplification System for First Strand cDNA Synthesis (Gibco BRL). The five antisense primers that were used corresponded to the MCl receptor (MC1 A 1; 5'-GCTGGCACGCTCTCG-3'; accession \# X65635) (13); MC2 receptor (MC2 A1; 5'-GTGGTGGGAGAAGAT-3'; accession \#D31952) (2, 10); MC3 receptor (MC3 A 1; 5'-AGTGCTGCTGTGGGG-3'; accession \# X74983) (4); MC4 receptor (MC4 Al; 5'-CATGTTGGTACCCTG-3'; accession \# AB009664); and MC5 receptor (MC5 A I; 5'-TGAAAACAATGCCGCAGC-3'; accession \#X76295 and \# L22527) (5, 11). Polymerase chain reactions (PCR) were performed in a $50 \mu \mathrm{L}$ solution containing $2 \mu \mathrm{L}$ cDNA, $200 \mu \mathrm{M}$ of each of the four deoxynucleotides, $100 \mathrm{pmol} \mathrm{MC}$ receptor sense and antisense primers, $20 \mathrm{mM}$ Tris- $\mathrm{HCl}(\mathrm{pH}$ 8.4), $50 \mathrm{mM} \mathrm{KCl}, 1.5 \mathrm{mM} \mathrm{MgCl}_{2}$, and $2.5 \mathrm{U}$ of Taq DNA polymerase (Gibco BRL). The five sense primers that were used corresponded to the MCl receptor (MC1 S1; 5'-TCGCCCATGTATTACTTC-3'; accession \# X65635); MC2 receptor (MC2 S1; 5'-TCCCCCATGTATTTTTTC-3'; accession \#D31952); MC3 receptor (MC3 S1; 5'-CCCATGTACTTCTTCCTG-3'; accession \# $\mathrm{X74983)}$; $\mathrm{MC4}$ receptor (MC4 S1; 5'ATACGGATGCCCAGAGCT-3'; accession $\mathrm{AB} 009664)$ (12); and $\mathrm{MC5}$ receptor (MC5 $\mathrm{S1}$; 5'-ACTCACCCATGTACTTCT-3'; accession \# $X 76295$ and \# L22527); the five antisense primers were those described above. The mixture was heated at $94^{\circ} \mathrm{C}$ for $3 \mathrm{~min}$ followed by PCR in a DNA thermal cycler for 45 cycles $\left(94^{\circ} \mathrm{C}, 25 \mathrm{sec}\right.$; $\left.45^{\circ} \mathrm{C}, 25 \mathrm{sec} ; 72^{\circ} \mathrm{C}, 1 \mathrm{~min}\right)$. PCR products were separated on $2 \%$ NuSieve/1\% SeaPlaque agarose gels, stained with ethidium bromide, and photographed. Selected PCR bands were excised and the DNA purified using a QIAEX II Gel Extraction Kit (QIAGEN). Ten percent $(2 \mu \mathrm{L})$ of the QIAGEN-purified PCR DNA was subsequently reamplified using nested primers under the same conditions as described above, with the exception that the annealing temperature was increased to $55^{\circ} \mathrm{C}$. PCR products were separated on $3 \%$ NuSieve/1\% SeaPlaque agarose gels. The nested $\mathrm{MCl}$ and $\mathrm{MC5}$ sense and antisense primers were: MC1 sense (MC1 S2; 5'-TGCCTGGCCCTGTCTGAC-3'); $\mathrm{MCl}$ antisense (MC1 A2; 5'-TGGGCAGCGTCACGATG-3'); MC5 sense (MC5 S2; 5'-GTGGCCGACATGCTGGT-3'); and MC5 antisense (MC5 A2; 5'-GGTCCAGATGCAGG(GA-3').

Macrophage total RNA was reverse-transcribed using five different gene-specific antisense $\mathrm{MC}$ receptor primers and amplified by PCR using pairs of sense and antisense primers corresponding to mouse $\mathrm{MC1}, \mathrm{MC2}, \mathrm{MC} 3, \mathrm{MC} 4$, and $\mathrm{MC} 5$ receptors. The PCR products were fractionated by gel electrophoresis on $2 \%$ NuSieve/1\% SeaPlaque agarose gels and a representative profile is shown in Fig. $1 \mathrm{~A}$.

A 440-base pair (bp) band of the expected size ( $438 \mathrm{bp}$ ) for the $\mathrm{MC} 1$ receptor was observed following PCR amplification (Fig. 1A). Similarly, a 330-bp band of the expected size (329 bp) for the MC5 receptor was observed. Macrophage MCl and MC5 PCR bands of the approximate expected size were also observed following RTPCR of DNase I-treated total RNA (data not shown). In control experiments, when reverse transcriptase was excluded from the reverse transcription step, no MC1- or MC5-specific bands were observed. Bands corresponding to the expected sizes of the MC2 (344 bp), MC3 (492 bp), or MC4 receptor (392 bp) PCR products were not observed.

To confirm the identity of the macrophage MC1 PCR product that was detected, macrophage and skin RT-PCR products ( $\sim 440 \mathrm{bp}$ ) of DNase I-treated total RNA were purified and reamplified at a higher annealing temperature $\left(55^{\circ} \mathrm{C}\right)$ using a pair of nested $\mathrm{MCl}$ sense and antisense primers. In both instances, a single band of the expected size for the MC1 receptor (243 bp) was observed on 3\% NuSieve/1\% SeaPlaque gels (Fig. 1B, left).

In order to verify the identity of the macrophage MC5 PCR product that was observed, macrophage and muscle RT-PCR products of DNase I-treated total RNA were purified and reamplified at a higher annealing temperature $\left(55^{\circ} \mathrm{C}\right)$ using a pair of nested MC5 sense and antisense primers. In both cases, a single band of the expected size for the MC5 receptor (266 bp) was observed on $3 \%$ NuSieve/1\% SeaPlaque gels (Fig. 1B, right). 

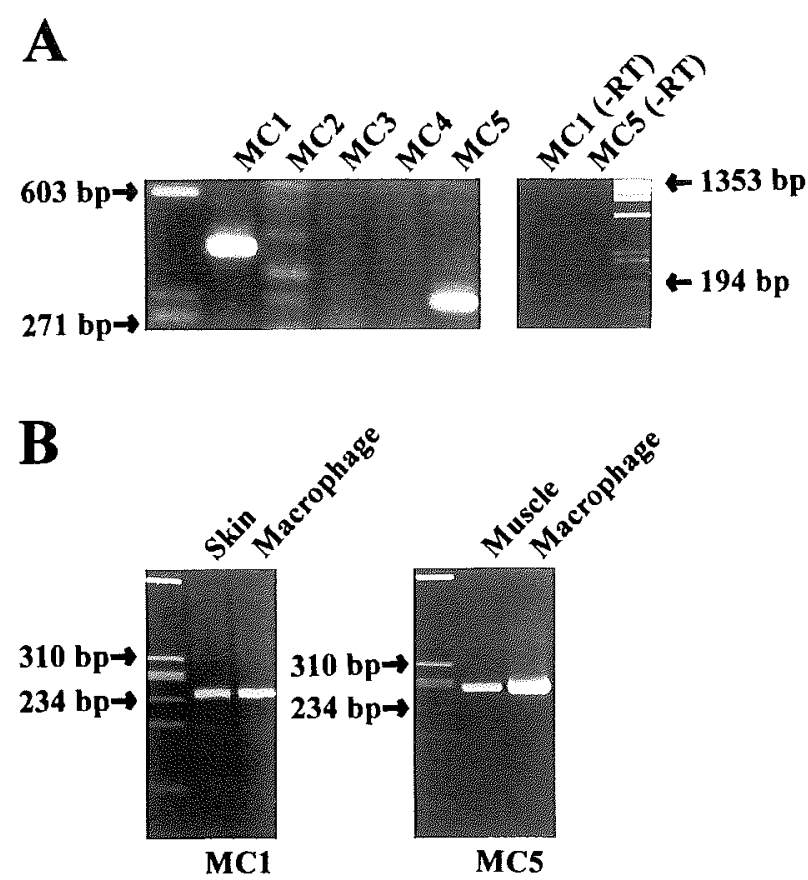

Fig. 1 MCl and MC5 receptor expression in cultured mouse peritoneal macrophages. (A) RT-PCR analysis of expression of $\mathrm{MC}$ receptor genes. The expected sizes of RT-PCR products are: $\mathrm{MCl}$ receptor (438 bp); MC2 receptor (344 bp); MC3 receptor (492 bp); MC4 receptor (392 bp); and MC5 receptor (329 bp). Macrophages expressed MC1 and MC5 receptor genes, but not $\mathrm{MC2}, \mathrm{MC} 3$, or $\mathrm{MC} 4$ receptor genes. MCl and MC5 RT-PCR products were not observed when reverse transcriptase was excluded from the reverse transcription step (-RT) in the right panel of A. (B) RT-PCR verification of the identity of macrophage $\mathrm{MCl}$ and MC5 receptor PCR products. Skin $\mathrm{MCl}$ receptor and macrophage $\mathrm{RT}-\mathrm{PCR}$ products from DNase I-treated total RNA were purified and reamplified using nested $\mathrm{MC} 1$ receptor primers in the left panel of B. Muscle MC5 receptor and macrophage RT-PCR products from DNase I-treated total RNA were purified and reamplified using nested MC5 receptor primers in the right panel of $\mathrm{B}$. In each case, a single band of the size expected for the MC1 receptor ( $243 \mathrm{bp}$ ) or MC5 receptor (266 bp) was observed. Size markers are (X174 RF DNA/ Hae III fragments (Gibco BRL).

In this study, of the five melanocortin receptor genes that have been cloned and characterized, we found that mouse macrophages expressed MC1 and MC5 receptor genes in vitro when genespecific antisense oligonucleotides primed the reverse transcription reaction (Fig. 1A). Receptor expression was not due to genomic DNA contam- ination, since specific $\mathrm{MCl}$ (438 bp) and MC5 (329 bp) RT-PCR products were observed even after DNase I removal of residual genomic DNA. To further confirm the identity of the macrophage MC1 and MC5 RT-PCR products, a second round of PCR was performed using pairs of nested MC1- and MC5-specific primers. Nonspecific DNA amplified by the first primers are very unlikely to contain sequences that will anneal the second pair of primers (15). In both instances, the sizes of the resulting PCR products matched those observed for the skin MC1 receptor (243 bp) and muscle MC5 receptor (266 bp) mRNAs (Fig. 1B). These data strongly suggest that $\mathrm{MCl}$ and MC5 receptor genes are expressed in cultured peritoneal macrophages.

MC2, MC3 and MC4 receptors could not be detected in mouse macrophages by the present RT-PCR methods. Concerning MC2 receptor, we could detected the receptor on mouse adrenal gland by the present methods (not illustrated). Adrenal gland expression of $\mathrm{MC} 2$ receptor has also been already reported (2). Therefore, possibility of the presence of $\mathrm{MC} 2$ receptor in mouse macrophages may be low. MC3 receptor expression was examined previously by a sensitive RNase protection assay (4). However, no signal was observed in adrenal gland, skin, pituitary, lung, thymus, heart, skeletal muscle, spleen, kidney, esophagus, stomach, duodenum, jejunum, ileum, colon, liver, pancreas, uterus, ovary, placenta, testis, prostate, or seminal vesicle of mouse. A very faint signal after 15 days of autoradiography was observed only in the basal region of the brain, i.e. hypothalamus, thalamus and striatum. We could not detected MC3 RT-PCR product in mouse cerebrum (not illustrated). Concerning MC4 receptor, mouse MC4 receptor partial cDNA sequence was just recently reported (12). To data, we could not find any report that examined tissue expression of MC4 receptor in mouse. The present study based on the present available scientific knowledgs concering MC3 and $\mathrm{MC} 4$ receptors may not be able to exclude the possibility of MC3 and MC4 receptor expression in mouse macrophages.

Melanocortin receptors are expressed in various mouse tissues. $\mathrm{MCl}$ receptor cDNA was cloned from a mouse melanoma cell line (13). The mouse $\mathrm{MC} 2$ receptor was cloned from an adrenal cell line of mouse origin, Y1 (10) and the receptor is expressed in mouse adrenal gland (2). The mouse MC3 receptor is expressed in the brain, but 
not in adrenal gland or skin $(4,12)$. The mouse MC4 receptor has been partially cloned from the anterior pituitary (12). Expression of the MC5 receptor in mouse was observed in skin, adrenal gland, bone marrow, spleen, thymus, gonad, uterus, skeletal muscle, lung, spleen and brain (5, 11). The melanocyte $\alpha$-melanocyte-stimulating hormone $(\alpha-\mathrm{MSH})$ receptor MC1 has been observed in a macrophage-like cell line, RAW 264.7. The present study demonstrated that primary culture cells of peritoneal macrophages have both MC1 and MC5 receptors. Each melanocortin receptor may have its specific function in different tissues.

We thank Dr. Randy Given of the University of Texas Medical Branch at Galveston for providing mouse skin and muscle tissue and Ms. Y. Takeda of Shimane Medical University for technical assistance. This work was supported by a Travel Grant for G.T.N. from the Foundation of Shimane Medical University for Education and Research to M.I.

\section{REFERENCES}

1. Alvarez-mon M., Kehrl J.H. and Fauci A.S. (1985) A potential role for adrenocorticotropin in regulating human B lymphocyte functions. J. Immunol. 135, 3823-3826.

2. Cammas F.M., Kapas S., Barker S. and Clark A.J.L. (1995) Cloning, characterization and expression of a functional mouse ACTH receptor. Biochem. Biophys. Res. Commun. 212, 912-918.

3. Chomcyznski P. and Sacchi, N. (1987) Single-step method of RNA isolation by acid guanidinium thiocyanatephenol-chloroform extraction. Anal. Biochem. 162, 156159.

4. Desarnaud F., Labbe O., Eggerickx D., Vassart G. and Parmentier M. (1994) Molecular cloning, functional expression and pharmacological characterization of a mouse melanocortin receptor gene. Biochem. J. 299, 367373.

5. Gantz I., Shimoto Y., Konda Y., Miwa H., Dickinson C.
J. and Yamada T. (1994) Molecular cloning, expression, and characterization of a fifth melanocortin receptor. Biochem. Biophys. Res. Commun. 200, 1214-1220.

6. Ichinose M., Sawada M. and Maeno T. (1994) Suppression of phagocytosis by adrenocorticotropic hormone in murine peritoneal macrophages. Immunol. Lett. 42, 161-165.

7. Johnson H.M., Smith E.M., Torres B.A. and Blalock J.E. (1982) Regulation of the in vitro antibody response by neuroendocrine hormones. Proc. Natl. Acad. Sci. USA 79, 4171-4174.

8. Johnson H.M., Torres B.A., Smith E.M., Dion L.D. and Blalock J.E. (1984) Regulation of lymphokine $(\gamma$ interferon) production by corticotropin. J. Immunol. 132, $246-250$.

9. Koff W.C. and Dunegan M.A. (1985) Modulation of macrophage-mediated tumocidal activity by netropeptides and neurohormones. J. Imnumol. 135, 350-354.

10. Kubo, M., Ishizuka, T., Kijima, H., Kakinuma, M. and Koike, T. (1995) Cloning of a mouse adrenocorticotropin receptor-encoding gene. Gene 153, 279-280.

11. Labbe O., Desarnaud F., Eggerickx D., Vassart G. and Parmentier M. (1994) Molecular cloning of a mouse melanocortin 5 receptor gene widely expressed in peripheral tissues. Biochemistry 33, 4543-4549.

12. Morooka Y., Oomizu S., Takeuchi S. and Takahashi S. (1998) Augmentation of prolactin release by $\alpha$-melanocyte stimulating hormone is possibly mediated by melanocortin 3 -receptors in the mouse anterior pituitary cells. 2001. Sci. $15,567-572$.

13. Mountjoy K.G., Robbins L.S., Mortrud M.T, and Cone R. D. (1992) The cloning of a family of genes that encode the melanocortin receptors. Science 257, 1248-1251.

14. Star R.A., Rajora N., Huang J., Stock R.C., Catania A. and Lipton J.M. (1995) Evidence of autocrine modulation of macrophage nitric oxide synthase by $\alpha$-melanocytestimulating hormone. Proc. Natl. Acad. Sci. USA 92, 8016-8020.

15. Watson J.D., Gilman, M., Witkowski J. and Zoller M. (1992) Recombinant DNA (2nd Ed.). W.H. Freeman and Co., New York.

16. Weigent D.A. and Blalock J.E. (1995) Associations between the neuroendocrine and immune systems. $J$. Leukoc, Biol. 57, 137-150.

17. Zwilling B.S., Lafuse W.P., Brown D. and Pearl D. (1992) Characterization of ACTH mediated suppression of MHC class II expression by murine peritoneal macrophages. J. Immunol. 39, 133-138. 